\title{
Conservation's New Look in the USA
}

\author{
By Stewart L. Udall
}

The last ten years have seen immense advances in the conservation field in the United States. Thanks to the hard spadework of the conservation bodies, the general attitude towards wildlife has changed from ignorant and unregarding exploitation to demands for wise use on a sustained yield basis; people's interest in and knowledge about conservation has made possible a long and varied list of legislation. More than any other one person the man responsible for this is Stewart Udall, for the past eight years Secretary of the Interior with charge of all conservation matters. On his retirement in January this year Mr Udall kindly accepted our invitation to sum up this remarkable 'new look' in the USA.

$7 \mathrm{HE}$ attitudes towards the conservation of natural resources, protec1 tion of the environment, and the qualities of a good life have changed greatly in the United States during the last half century. The changes in the last decade may well equal those which occurred during the previous forty years.

National attitudes and policies have evolved from a philosophy of total harvest, complete exploitation, and disregard (or ignorance) of future consequences, through concentration on regulation and preservation, toward wise use, restoration or rehabilitation, and sustained yields. From a subject of concern to a few generally well educated and farsighted individuals, conservation has become a major issue to many of our citizens. The plight of alligators stricken by drought and suffering the depredations of poachers, the scars of strip mining, or a controversy over the establishment of a new park are examples of 'conservation problems' that attract attention of national news media and prompt both children and adults to deluge their representatives with demands for protective action. Air and water pollution and their consequences are becoming known to even the smallest children through the medium of television. High school and even grade school students now study basic science material which only a few years ago was covered only in college.

Recent years have seen the passage of significant legislation reflecting the new national awareness that preserving the environment so that man may live, rather than merely exist, will require positive action. There is even a suspicion on the part of many that inaction, the continued degradation of the environment, and the unchecked increase of the human population would eventually result in an uninhabitable globe.

National standards for water quality are being adopted, and pollution abatement is being enforced. Local, state, and national measures aimed at reducing air pollution from such diverse sources as automobile exhaust, heating plants, and garbage disposal have been adopted. Hearings are being held on and consideration is being given to banning the use of persistent insecticides such as DDT. Studies are being made on the preservation of estuaries, so vital to our fishery recources. Pilot programmes to study 
techniques for restoring land scarred or denuded by strip mining have been instituted. Highway engineers are now required to consider factors other than cost and mileage - for instance, the effects on parks, historic sites, and wildlife areas - when planning new routes.

A new concept of the national responsibility for the quality of life (as distinct from the material well-being) of our citizens has been developed. National recreation areas and seashores are being acquired and developed for the use and enjoyment of all the people. These are distinct from our traditional national park concept of acquiring areas to preserve outstanding features from alteration. The Federal Government is sharing the cost of recreational and park developments with state and local governments. But intensive development is not our total objective. Many of our people delight in completely natural areas. Scenic rivers have been designated on which no dams will be constructed. Large tracts of Federal land have been set aside as wilderness where no development will be allowed and motor travel is prohibited. On a smaller scale, organisations such as the Nature Conservancy and the National Audubon Society have purchased sanctuaries to preserve remnants of native flora and fauna in rapidly developing regions.

Few governmental programmes so captured the public fancy as the Department of the Interior's work with endangered species. Virtually no one had heard of a black-footed ferret only three years ago; now it is featured in national magazines and television documentaries. Even the financial press has devoted front-page coverage to the status of timber wolves and grizzly bears. Congress responded to the national concern. The Endangered Species Preservation Act, passed in 1966, authorised the Secretary of the Interior to establish a programme for the preservation of endangered species of fish and wildlife and belatedly implemented the 1940 Inter-American Treaty on Nature Protection and Wildlife Protection.

Our Bureau of Sport Fisheries and Wildlife is co-ordinating a national effort to preserve endangered species of native wild fauna in their natural habitat. The job demands wide co-operation-private, organisational, state, and Federal.

After decades of being restricted by dependence on sportsmen's funds to exclusive concern for game species, state fish and wildlife agencies are beginning to take interest in non-game wildlife. Arizona and California have established wildlife investigation units to study and manage non-game wildlife. Legal protection is being granted to non-game species. All birds of prey are protected in Colorado; bounties have been removed and canids and felines classified as game animals in most states. A model law for the protection of endangered species is being introduced in the next session of the Nebraska Legislature.

Many landholding businesses have issued directives that provide protection for endangered wildlife on lands under their control. Oil companies have suspended coastal drilling when whooping cranes were in their neighbourhood. Both timber and oil firms proudly feature their conservation activities in full page advertisements in national magazines. Communities and housing developers are requesting professional advice on the 
preservation of natural areas. Individual landowners, Indian tribes, and corporations from Florida to the Pacific North-west are protecting eagle nesting sites on several million acres.

It is, perhaps, redundant to say how pleased I am with the developments over the last few years. The United States has taken the first few steps to retrace the path towards a ruined environment which it followed for so long. Unfortunately, there are still many who profit from deplorable conditions, oppose change, and are unwilling to sacrifice their own shortterm economic gains for long-term benefits. I believe that recognition of the public interest will eventually reverse this attitude. Correcting longpast mistakes can be expensive, and the technology to solve all our environmental problems is not yet available, but I believe we are well on the way.

\title{
Fur Seals off California
}

\begin{abstract}
A BREEDING colony of northern fur seals, up to 100 strong, was discovered $A$ last summer on an island off the California coast. Hitherto these fur seals have been known to breed only on the far distant Pribilof Islands of Alaska and a few islands in the Bering and Okhotsk Seas, where, after being nearly exterminated, careful management in the last $\mathbf{5 0}$ years has built the numbers up to an estimated four million. The island, San Miguel, is fortunately part of a proposed national park and is in restricted waters under US navy control.
\end{abstract}

\section{Tortoise Drain in Morocco}

EVERY year some half-a-million tortoises are exported from Morocco to Ereat Britain, and a similar number go to other countries. Nothing is known of the effect of these enormous exports on the tortoise populations, but it seems unlikely that they can stand this heavy drain. In order to find out the FPS, through the FPS/WWF Revolving Fund, is supporting a study of these tortoise populations in Morocco this spring by a herpetologist, M. R. K. Lambert, who will try to establish the size and age structure of the populations.

\section{Leopards in South Arabia}

R R. L. GREEN writes that in 1962, while serving with the Federal Army of South Arabia, he came across leopard tracks in southern Arabia, about 200 miles north-east of Aden near the western end of the Wadi Hadramaut. The Arabs with him, some of them local men, agreed that leopard existed in the area, although rarely seen, In 1963 a British intelligence officer living in the Dhala amirate, about 80 miles north of Aden, told Dr Green how he had recently come across a party of Yemeni tribesmen carrying the body of a leopard they had shot about 50 miles east of Taiy.

\section{The Spotted Cat Trade}

ESTIMATES by the United States fur trade put the annual world catch of spotted cats in 1967-68 at about half a million animals, of which about 350,000 are imported into the United States. But, says the trade, only about 12 per cent stay in the United States; the rest are re-exported after processing. The world catch figures are: ocelot cats, 200,000; poludas, 60,000; ocelots, $180 / 200,000$; jaguars, 3500/4000; leopards, over 20,000. For tigers and cheetahs only the US import figures could be given: 200 and 800 respectively, plus a small number of snow leopards. 